\title{
ACTIVE HAPTIC EXPLORATION OF DEFORMABLE OBJECTS
}

\author{
DOMingueZ-RAmireZ, O.A. \& PARRA-Vega, V.
}

Abstract: An haptic interface allows the interaction among a human operator and a virtual environment defined in a computer, the haptic interaction with a virtual object establishes a kinesthetic sensation to the user. During the random exploration of the virtual object in the haptic device workspace, the human operator perceives reaction forces and of opposition to its voluntary motion, these can arise for the presence of virtual objects synthesized with base in the methods dedicated for this purpose wherein the main scheme, in many works, is based on the penalty method. However, when the object is deformable, the penalty method cannot compute properly the shape and roughness since the contact force ignores the inherent deformation of the object. It is well accepted that to better perceive a given virtual object, it is relevant to yield some surface properties of the object, for instance the shape through the normal contact force, the roughness by the sliding friction, and the texture as a combination of both of them. In contrast to the penalty method, if the contact force is computed using the constrained Lagrangian, this force depends on the dynamic deformation of the object. In this work, a constrained Lagrangian-based oriented framework is proposed to compute the contact force dynamically, in such a way that it can easily realize these effects over implicit dynamical objects. Experimental results using PHANToM on deformable and undeformable virtual objects with surface properties are presented and discussed.

Key words: Haptic Interface, shape, texture, roughness, exploration, control, constrained motion, free motion
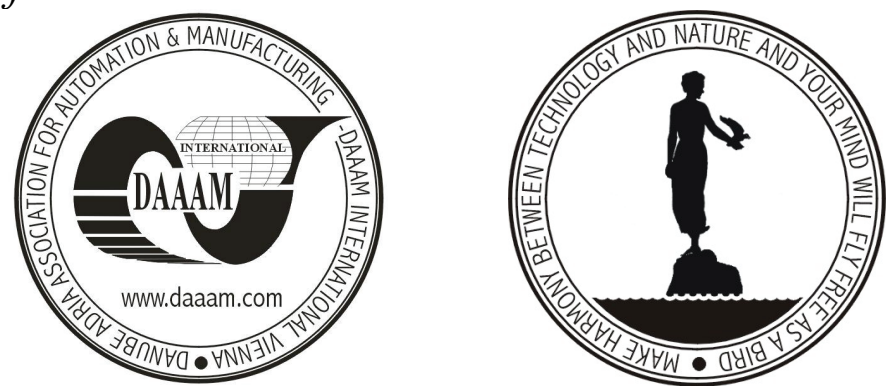

Authors' data: Prof. Dominguez-Ramirez O.[mar] A.[rturo]*, Prof. Parra-Vega V.[icente] ${ }^{* *}$, *Autonomous University of the Hidalgo State - Institute of Basic Sciences and Engineering, Pachuca, Hidalgo, Mexico, ** Research Center for Advanced Studies - Cinvestav,Saltillo Campus, Mexico, omar@uaeh.reduaeh.mx, vparra@cinvestav.mx

This Publication has to be referred as: Dominguez-Ramirez, O.A. \& Parra-Vega, V. (2006). Active Haptic Exploration of Deformable Objects, Chapter 17 in DAAAM International Scientific Book 2006, B. Katalinic (Ed.), Published by DAAAM International, ISBN 3-901509-47-X, ISSN 1726-9687, Vienna, Austria DOI: $10.2507 /$ daaam.scibook.2006.17 